\title{
KIR/HLA ligands immunogenetics markers associated with outcome of hepatitis $B$ virus infection in the Bulgarian population
}

\author{
Viktoria Varbanova a, Georgi Popov ${ }^{\mathrm{b}}$, Veneta Grigorova ${ }^{\mathrm{c}}$, Diana Petrova ${ }^{\mathrm{d}}$, Elissaveta Naumova ${ }^{\mathrm{e}}$, Anastasiya Mihaylova ${ }^{\mathrm{e}}$
}

Background. Hepatitis B virus (HBV) infection is one of the most common infections worldwide, having negative impact on world health due to the tendency for chronification with late complications such as liver cirrhosis and hepatocellular carcinoma. Natural killer (NK) cells as part of innate antiviral defense influence the clinical course of HBV infection: elimination of the virus or chronic disease.

Aim. Therefore, we investigated the polymorphisms of the main gene systems, regulating NK-cell function: killer cell immunoglobulin-like receptors (KIRs) and their appropriate HLA class I ligands in $144 \mathrm{HBV}$ infected patients (124 chronic carriers and 20 spontaneously recoved) and 126 ethnically matched healthy controls from the Bulgarian population in a case-control study.

Methods. KIRs and HLA ligands were determined by PCR-SSP or PCR high-resolution typing methods.

Results. KIR2DL5B allele variant was significantly less frequent in spontaneously recovered (SR) patients compared to healthy controls $(10.0 \%$ vs. $45.5 \%$, Porr $=0.006)$. The presence of KIR3DL $1 * 004$ allele was higher in chronic HBV carriers $(\mathrm{CH})$ than in controls $(33.1 \%$ vs. $17.6 \%$, Porr $=0.036)$. Additionally, SR patients differed from healthy individuals by the lower frequency of HLA-Bw4 $4^{\| 180}$ group ligands (30.0\% vs $\left.63.7 \%, P=0.015\right)$. Three KIR genotypes were found more frequent in healthy in comparison with HBV infected individuals: ID2 (13.5\% vs $5.6 \%, P=0.025)$, KIR genotype containing 6 activating KIRs ( $18.0 \%$ vs $7.6 \%, P=0.017)$, and KIR genotype composed of 4 activating and 5 inhibitory KIRs ( $23.8 \%$ vs $5.6 \%, P=0.001$ ).

Conclusion. These data suggest that inherited KIR and HLA class I ligand polymorphisms may influence the clinical course of HBV infection.

Key words: killer immunoglobuline-like receptors, KIR HLA ligands, hepatitis B infection

Received: February 18, 2020; Revised: September 17, 2020; Accepted: September 17, 2020; Available online: September 21, 2020 https://doi.org/10.5507/bp.2020.043

(c) 2021 The Authors; https://creativecommons.org/licenses/by/4.0/

${ }^{a}$ Clinic of Hematology, Military Medical Academy, MHAT, Sofia, Bulgaria

${ }^{b}$ Clinic of Infection Diseases, Military Medical Academy, MHAT, Sofia, Bulgaria

'Department of Cardiac Surgery, Acibadem City Clinic, Tokuda Hospital, Sofia, Bulgaria

${ }^{d}$ Clinic of Propaedeutics in Internal Diseases, University Hospital "Alexandrovska", Medical University, Sofia, Bulgaria

eClinic of Clinical Immunology and Stem Cell Bank, University Hospital "Alexandrovska", Medical University, Sofia, Bulgaria

${ }^{e}$ Clinic of Clinical Immunology and Stem Cell Bank, University Hospital "Alexandrovska", Medical University, Sofia, Bulgaria, mihaylova_ap@ abv.bg

Corresponding author: Viktoria Plamenova Varbanova, e-mail:viktoriia1982@abv.bg

\section{INTRODUCTION}

Viral hepatitis is one of the most common diseases worldwide. According to the World Health Organization approximately 2.5 billion people have been infected with Hepatitis B virus (HBV), and approximately $3.5 \%$ of the global population, or 257 million people are chronic carriers of the virus ${ }^{1,2}$. In Bulgaria, the frequency of the HBV carriers is $3.8 \%$, ranging dependent on the district from $1.9 \%$ to $5.3 \%\left(\right.$ ref. $\left.^{3}\right)$, which places the country in the moderate endemicity regions.

The high distribution of the HBV infection, the severity of the disease and the associated late complications and mortality, define HBV as one of the major health and social problems in the modern society. Although the etiologic agent of HBV infection has been known for more than 50 years, the pathogenesis of chronic HBV infection remains unknown. It is considered that $\mathrm{HBV}$ is not directly cytopathogenic. The host antiviral immune response may lead both to the removal of the virus, as well as the destruction of the infected hepatocytes and a liver failure. In a chronic infection the effect on the liver is mainly regulated by the host immune system and related cellular immune responses.

Natural killer (NK) cells are the main population of the non-specific cellular immune defense and their function is to destroy virus-infected and transformed cells, and thus to prevent the advance of the liver damage and the occurrence of hepatocellular carcinoma $a^{4-6}$. NK cell function is controlled by a complex system of interactions between diverse inhibitory and activating receptors and ligands whose expression is genetically predetermined. In this sense the most well-known and relevant NK cell receptors are those of the immunoglobu- 
lin superfamily (Killer immunoglobulin-like receptors KIRs) and their ligands ${ }^{7-11}$. Currently 15 KIR genes are decribed (KIR2DL1, KIR2DL2, KIR2DL3, KIR2DL4, KIR2DL5A, KIR2DL5B, KIR2DS1, KIR2DS2, KIR2DS3, KIR2DS4, KIR2DS5, KIR3DL1, KIR3DS1, KIR3DL2, KIR3DL3) and two pseudogenes (KIR2DP1 and $K I R 3 D P 1)$, which encode the inhibitory - 2DL1, 2DL2, 2DL3, 2DL4, 2DL5A, 2DL5B, 3DL1, 3DL2, $3 \mathrm{DL} 3$ and the activating - 2DS1, 2DS2, 2DS3, 2DS4, 2DS5, 3DS1 KIR receptors ${ }^{12}$. KIR genes have been divided into two haplotypes $A$ and $B$ depending on the presence of specific genes ${ }^{12}$.

Ligands for most KIRs are specific motifs of the human leukocyte antigen (HLA) class I molecules. Dimorphism in the HLA-C $\alpha 1$ domain, defines two HLA-C groups - C1 (Ser77/Asn80) and C2 (Asn77/ Lys80), which are ligands for two different receptors of the KIR2DL and KIR2DS receptor groups ${ }^{8}$. HLA-B allotypes with Bw4 motif in position 77-83 are ligands for the inhibitory KIR3DL1 ( ref. $^{9}$ ). The binding affinity between receptor and ligand depends on the amino acid residue at $80^{\text {th }}$ position in the HLA molecule and is stronger when HLA-Bw4 alleles have isoleucine (Ile80) compared to those with threonine (Thr80) at this position ${ }^{10}$. KIR3DL1 recognizes certain HLA-A alleles with Bw4 motifs as well ${ }^{11}$. Consequently, the functional activity of KIRs and the activating or inhibiting signals which they transmit would be dependent on the KIRs/KIR HLA class I ligands genotype of the individual. Recently, considerable data from case-control studies demonstrate the hypothetical role of KIRs and their HLA ligands as genetic factors involved in viral clearance ch,5-21. $^{4}$.

Therefore, we studied a complex of immunogenetic factors related to KIRs and their HLA class I ligands in infected and non-infected with HBV individuals from the Bulgarian population with the aim to reveal a potential effect of immunogenetic components on the outcome of HBV infection. Better understanding on the mechanisms that govern antiviral immune responses of the host in relation to the genetic diversity would provide opportunities to improve and personalize therapeutic interventions in $\mathrm{HBV}$ infected patients.

\section{MATERIAL AND METHODS}

\section{Study population}

One hundred twenty-four patients with chronic hepatitis B (86 males and 38 females; $44 \pm 27$ years old, ranged from 18 to 73 years) and twenty individuals spontaneously recovered from acute $\mathrm{HBV}$ infection (11 males and 9 females; $44 \pm 13.5$ years; ranged from 31 to 58 years old) were included in the study. The patients were diagnosed and treated at the Department of Gastroenterology, Clinic of Propaedeutics in Internal Diseases, University Hospital "Alexandrovska" and at the Clinic of Infectious Diseases, Military Medical Academy, Sofia, Bulgaria. Patients were classified in two groups - chronic HBV carriers (HBsAg positive, anti-HBs negative, anti-HBc positive) and spon- taneously resolved $\mathrm{HBV}$ infection ( $\mathrm{HBs} \mathrm{Ag}$ negative, anti-HBs positive, anti-HBc positive) after clinical and laboratory evaluation according to predefined inclusion and exclusion criteria previously described in detail ${ }^{22}$. The healthy controls consisted of 126 randomly selected unrelated individuals ( 67 females and 59 males, aged $46.6 \pm 11.9$ years) from the Bulgarian population, without any family history of inherited diseases or any medical history of viral hepatitis, HIV infection, and other diseases such as diabetes, malignancy or autoimmune diseases. These subjects were with normal liver function and negative serological markers for viral hepatitis.

Written and informed consent was obtained from patients and healthy controls. The study was approved by the local ethics committee and National Scientific Fund (DTK02/12-2009).

\section{Genotyping}

DNA was extracted from peripheral blood by iPrep PureLink ${ }^{\circledR}$ gDNA $^{\mathrm{TM}}$ Blood kit and iPrep ${ }^{\mathrm{TM}}$ Purification instrument (Invitrogen, USA).

KIR genotyping was performed by PCR-SSP method with 24 locus specific primers using commercially available Olerup SSP ${ }^{\circ}$ KIR typing kit (Olerup SSP AB, Sweden). The results obtained were interpreted using the worksheet provided by the manufacturer which allows detection of 16 KIR genes and pseudogenes, differentiation of KIR2DL5A, KIR2DL5B, KIR3DL1*004 alleles and two groups KIR2DS4 alleles (group 1 - KIR2DS4*001 from group 2 - KIR2DS4*003/004/006/007). Two approaches were used for KIR HLA ligands determination - direct typing and/or indirectly. The direct genotyping was performed with commercially available Olerup SSP ${ }^{\circledR}$ KIR HLA ligand typing kit (Olerup SSP AB, Sweden) which distinguishes HLA-C1, $-\mathrm{C} 2$, -Bw $4^{\mathrm{Ile} 80},-\mathrm{Bw} 4^{\mathrm{Th} 80}$ and $-\mathrm{A}^{\mathrm{Bw} 4+}$ ligand groups. The indirect determination used KIR ligand calculator ${ }^{23}$ based on high resolution typing of HLA-A, -B, -C alleles (AlleleSEQR HLA-A, -B and -C $\mathrm{PCR} /$ Sequencer Kit, Atria Genetics, USA) as previously described $^{24}$.

KIR haplotypes and genotypes were defined in accordance with the allele frequency net database (AFND) $\left(\right.$ ref. $\left.^{25}\right)$.

\section{Statistical analysis}

The frequencies of KIRs, KIR haplotypes, genotypes, KIR HLA class I ligands, and KIR/HLA ligand combinations were determined by direct counting. The comparative analysis between the different groups was performed by Pearson's chi-square test and Fisher exact test. Statistical analysis was done using SPSS for Windows, version 16.0 (SPSS Inc., Chicago, IL). All $P$-values less than 0.05 were considered to be statistically significant. Bonferroni-adjusted significance test was applied for pairwise comparisons in case of multiple number of comparisons. The corrected p-value $\left(\mathrm{P}^{\mathrm{corr}}\right)$ was obtained multiplying the uncorrected p-value by the number of comparisons made. Odds ratio (OR) and 95\% Confidence Intervals (CI) were calculated to variables with significant 
Table 1. KIR genes distribution in HBV infected patients and healthy controls.

\begin{tabular}{|c|c|c|c|}
\hline KIR gene & $\begin{array}{c}\mathrm{HC}(\mathrm{n}=126) \\
\mathrm{n}(\%)\end{array}$ & $\begin{array}{c}\text { CHB }(n=124) \\
n(\%)\end{array}$ & $\begin{array}{c}\text { SRI }(n=20) \\
n(\%)\end{array}$ \\
\hline 3DL2; 3DL3; 3DP1 & $126(100)$ & $124(100)$ & $20(100)$ \\
\hline 2DL4 & $125(99.2)$ & $124(100)$ & $20(100)$ \\
\hline 2DP1 & $122(96.8)$ & $123(99.2)$ & $20(100)$ \\
\hline 2DL1 & 118 (93.7) & $119(96.0)$ & $19(95.0)$ \\
\hline 2DL2 & $76(60.3)$ & 78 (62.9) & $14(70.0)$ \\
\hline 2DL3 & $108(85.7)$ & $111(89.5)$ & $19(95.0)$ \\
\hline 2DL5 & $82(65.1)$ & $67(54.0)$ & $10(50.0)$ \\
\hline 2DL5A & $42(34.7)^{\#}$ & $45(36.3)$ & $7(35.0)$ \\
\hline \multirow[t]{3}{*}{ 2DL5B } & $40(45.5)$ & $42(33.9)$ & $2(10.0)$ \\
\hline & & & $P=0.003 ; P^{\text {corr }}=0.006$ \\
\hline & & & OR $0.13[0.02-0.63]$ \\
\hline 2DS1 & $57(45.2)$ & $53(42.7)$ & $6(30)$ \\
\hline 2DS2 & $82(65.1)$ & $77(62.1)$ & $14(70.0)$ \\
\hline 2DS3 & $48(38.1)$ & $42(33.9)$ & $4(20.0)$ \\
\hline 2DS4 & $116(92.1)$ & $116(93.5)$ & $20(100)$ \\
\hline 2DS4norm & $18(20.2) \#$ & $35(28.5)$ & $8(40.0)$ \\
\hline 2DS4del & $70(78.7)^{\# \#}$ & $107(86.3)$ & $18(90.0)$ \\
\hline 2DS5 & $48(38.1)$ & $40(32.3)$ & $6(30.0)$ \\
\hline 3DS1 & $60(47.6)$ & $47(37.9)$ & $6(30.0)$ \\
\hline 3DL1 & $114(90.5)$ & 114 (91.9) & $20(100)$ \\
\hline \multirow[t]{3}{*}{$3 \mathrm{DL} 1 * 004$} & $13(17.6)^{\S}$ & $41(33.1)$ & $5(26.3)$ \\
\hline & & $P=0.018 ; P^{\text {corr }}=0.036$ & \\
\hline & & OR 2.3[1.1-4.7] & \\
\hline
\end{tabular}

HC - healthy controls, CHB - chronic hepatitis B, SRI - subjects with spontaneously resolved HBV infection, KIR - Killer immunoglobulin-like receptor, OR - odds ratio,

[ ] 95\% Confidence Interval, ${ }^{\#} \mathrm{n}=85,{ }^{\# \#} \mathrm{n}=89,{ }^{\S} \mathrm{n}=74, P^{\text {corr }}$ - Bonferroni-corrected $P$-values.

differences in order to estimate the associations between genetic factors and HBV infection.

\section{RESULTS}

\section{KIR genes/pseudogenes}

The distribution of KIR genes in patients and healthy controls is presented in Table 1.

Our data demonstrated that the frequencies of KIR genes were not significantly different between patients' groups and controls, except of KIR2DL5B and KIR3DL1*004 alleles. KIR2DL5B was found in lower frequency in both subgroups of patients compared to unrelated healthy individuals but the difference was statistically significant only for the patients with resolved HBV infection. A higher frequency of the functionally inert variant of the KIR3DL1 gene (KIR3DL1*004) was found among all $\mathrm{HBV}$ infected compared to controls, the difference being significant for the chronic hepatitis B subgroup.

To determine whether there were associations with the risk of chronicity of HBV infection, a comparison of KIR frequencies between the two subgroups of patients - chronic carriers and spontaneously resolved infection was made, assuming that both cohorts were exposed to a common environmental factor - hepatitis B virus. The analysis applied showed no significant differences.

\section{KIR genotypes}

Forty-one different genotypes were determined according to the presence/absence of individual KIRs among the patients and healthy controls, whose characteristics and frequencies are presented in Table 2. The comparison between the two groups showed lower frequency of KIR genotype ID2 [ $P=0.025$; OR 0.38 (95\% CI 0.14-0.85)] in the patients' group.

No statistically significant differences were found between HBV infected patients and healthy controls according to the distribution of KIRA and KIRB haplotypes and their combinations. KIR profiles determined by the number of activating and inhibitory KIR genes were also analyzed (data not shown). KIR profile containing six activating genes was more frequent in controls compared to patients [ $18.0 \%$ vs. $7.6 \%, P=0.017$; OR 0.4 (95\% CI $0.2-0.9)]$.

Additionally, the ratio between the number of activating and inhibitory KIR genes was calculated for all individuals according to the model of Karabon et al. ${ }^{26}$. Ratios ranged from 0.17 (prevalence of inhibitory KIR genes) to 1.20 (overrepresentation of activating KIR genes, data not shown). KIR genotype with ratio 0.2 (1 activating KIR/5 inhibitory KIRs) was the most frequent both in $\mathrm{HBV}$ infected and healthy individuals with a slightly higher incidence in the patients. KIR genotype corresponding to ratio 0.67 ( 4 activating/ 6 inhibitory genes) was significantly less frequent in patients compared to controls [5.6\% vs. 23.8\%; $P=0.001$; OR 2.5 (95\% CI 0.98-6.5)]. 
Table 2. KIR genotypes distribution in HBV infected individuals and healthy controls.

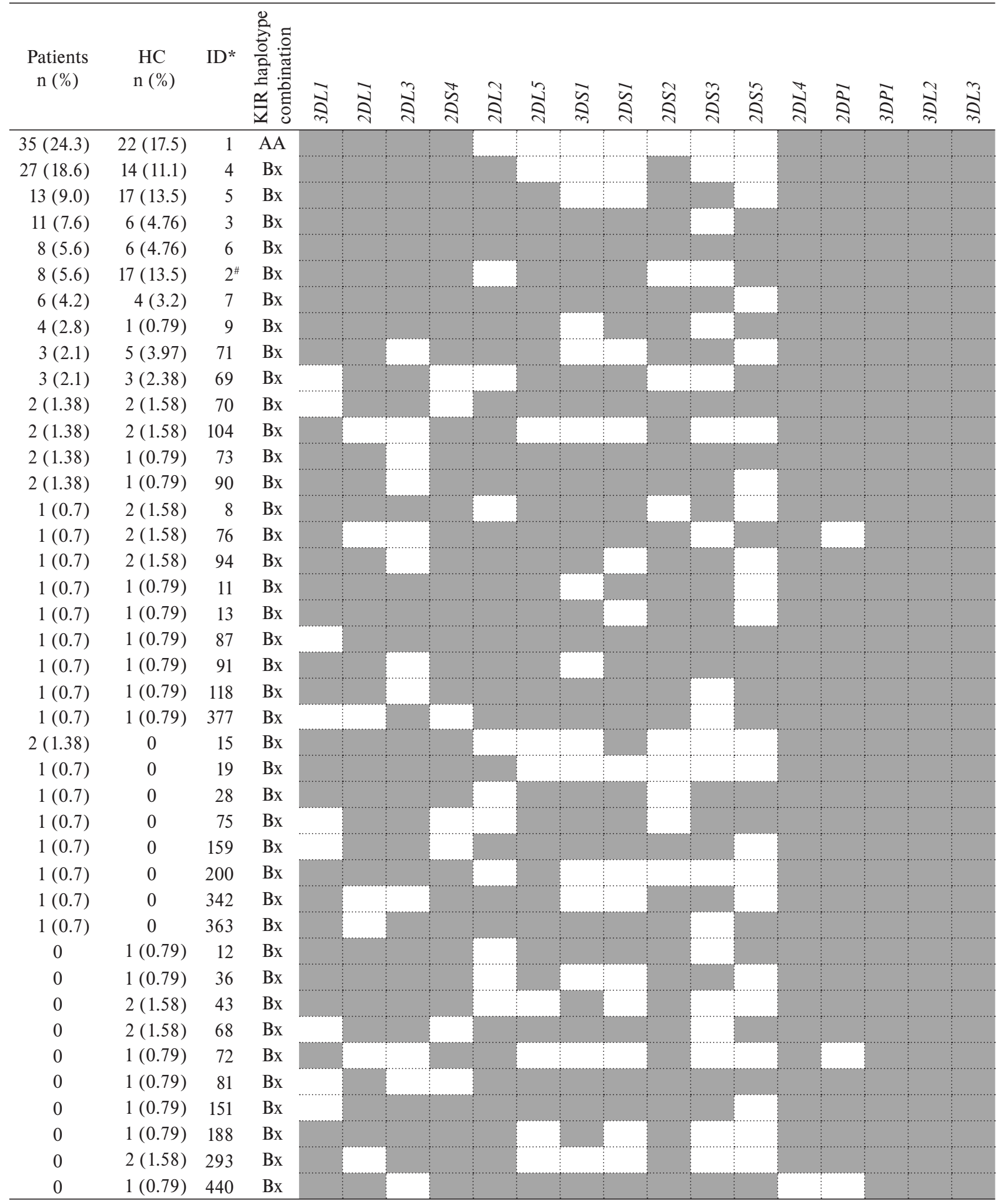

The filled squares correspond to the presence of the KIR gene and the empty ones to the absence of the KIR gene; *ID - Genotype identification number defined according to http://www.allelefrequencies.net/kir6001a.asp, \# - statistically significant 
Table 3. Distribution of KIR HLA class I ligands in HBV infected patients and healthy controls.

\begin{tabular}{|c|c|c|c|}
\hline KIR ligand & $\begin{array}{c}\mathrm{HC}(\mathrm{n}=113) \\
\mathrm{n}(\%)\end{array}$ & $\begin{array}{c}\text { CHB }(n=124) \\
n(\%)\end{array}$ & $\begin{array}{c}\text { SRI }(\mathrm{n}=20) \\
\mathrm{n}(\%)\end{array}$ \\
\hline HLA-C1 & $95(84.1)$ & $91(73.4)$ & $15(75.0)$ \\
\hline HLA-C2 & $75(66.4)$ & $89(71.8)$ & $14(70.0)$ \\
\hline HLA-C1C1 & $37(32.7)$ & $36(29.0)$ & $6(30.0)$ \\
\hline HLA- C1C2 & $57(50.4)$ & $55(44.4)$ & $9(45.0)$ \\
\hline HLA-C2C2 & $19(17.0)$ & $33(26.6)$ & $5(25.0)$ \\
\hline HLA- $B^{\mathrm{Bw} 4}$ & $84(74.3)$ & $83(66.9)$ & $11(55.0)$ \\
\hline HLA-B $^{\text {w4lle }} 80$ & $72(63.7)$ & $62(50.0)$ & $\begin{array}{c}6(30.0) \\
P=0.005 ; P^{\text {corr }}=0.015 \\
\text { OR 0.24 }[0.09-0.7]\end{array}$ \\
\hline HLA-Bw4 $4^{\text {Thr80 }}$ & $9(8.0)$ & $18(14.5)$ & $4(20.0)$ \\
\hline $\mathrm{HLABw}^{4 \mathrm{Ile} 80 \mathrm{Thr} 8} 0$ & $3(2.7)$ & $3(2.4)$ & $1(5.0)$ \\
\hline HLA- $\mathrm{A}^{\mathrm{Bw} 4}$ & $32(33.7)$ & $48(38.7)$ & $9(45.0)$ \\
\hline
\end{tabular}

\section{KIR ligands}

Analysis of KIR HLA C ligand frequencies showed no differences in the distribution between healthy controls and patients with $\mathrm{HBV}$ infection, both chronic $\mathrm{HBV}$ carriers and spontaneously recovered patients (Table 3 ).

The next step was to determine the distribution of HLA class I ligands for KIR3DL1 (alleles with Bw4 motif) in the subjects studied, but no statistically significant differences were revealed between patients and healthy controls, and between patients' subgroups as well. (Table 3).

When considering the amino acid (isoleucine or threonine) present at position 80 of the HLA-Bw4 molecule, HLA-Bw4Ile80 KIR ligands were significantly less frequent in HBV infected than controls (HBV infected patients $-47.2 \%$ vs healthy controls $-63.7 \%$, $P^{\text {corr }}=0.016$ ). Low frequency of HLA-Bw4Ile 80 positive individuals was observed in both patient subgroups (Table 3), but the difference was statistically significant for spontaneously recovered individuals. Although the lower incidence of KIR HLA-Bw $4^{\text {Ile } 80}$ ligands was more pronounced in the recovered subjects $(30.0 \%)$ compared to patients with chronic hepatitis B $(50.0 \%)$, no significant difference was found between both patients' cohorts $\left(P^{\text {corr }}>0.05\right)$.

\section{KIR/ HLA ligand combinations}

Frequencies of KIR/HLA class I ligand combinations were analyzed and compared between both healthy controls and patient groups, as well as between patients' subgroups (chronic HBV carriers compared to spontaneously resolved infection). Of 48 possible combinations, in which at least the receptor or ligand or both are present (inhibitory KIR/HLA class I ligand: 2DL1/ HLA-C2, 2DL2/3/ HLA-C1, 3DL1/ HLA-B ${ }^{\text {Bw4 }}$, 3DL1/ HLA-A ${ }^{\text {Bw4; }}$ activating KIR/HLA class I ligand: 2DS1/HLA-C2, 2DS2/HLA-C1, 3DS1/ HLA-B ${ }^{\mathrm{Bw} 4}$, 3DS1/ HLA-A ${ }^{\mathrm{Bw} 4}$ and inhibitory KIR/activating KIR/HLA class I ligand: 2DL1/2DS1/ HLA-C2, 2DL2/L3/2DS2/HLA-C, 3DL1/3DS1/HLA$\mathrm{B}^{\mathrm{Bw} 4}$, 3DL1/3DS1/HLA-A ${ }^{\mathrm{Bw} 4}$, data not shown), the only difference found was a tendency for higher frequency for the non-functional combination 3DL1(+)/3DS1(-)/HLA$\mathrm{B}^{\mathrm{Bw} 4}(-)$ in spontaneously resolved $\mathrm{HBV}$ infections [30.0\%; $\left.P=0.023, P^{o r r}=0.092\right]$ and chronic HBV carriers $[21.0 \%$, $\left.P=0.017, P^{c o r r}=0.068\right]$ compared to controls $(9.7 \%)$.

\section{DISCUSSION}

The essential role of NK cells in antiviral defense is undeniable. Data on the influence of the KIR genetic background for HBV disease susceptibility, spontaneous recovery or chronicity are controversial $1^{4-6,13,21-27}$.

In the present study, the role of two major genetic systems involved in the regulation of NK cell function - KIRs and KIR HLA class I ligands was investigated for the first time in hepatitis B viral infection (chronic carriers and recovered) in the Bulgarian population. The inhibitory KIR2DL5B allelic variant was found to have the lowest incidence in the subgroup of spontaneously resolved $\mathrm{HBV}$ infection, but the difference was significant only comparing to healthy controls and not to chronic carriers. The role of KIR2DL5 gene and its allelic variants for NK activity regulation is supported by the finding of other researchers as Shah-Hosseini et al. ${ }^{16}$ who demonstrated a higher frequency of KIR2DL5A allele in HBV recovered individuals compared to controls. The higher distribution of inhibitory KIR3DL1*004 observed by us in chronic HBV carriers may suggest increased NK-cell inhibition in chronic disease, although some data demonstrate lack of expression of the encoded receptor ${ }^{28}$.

In support of the hypothesis that NK-cell antiviral activity may be influenced by a genetically predetermined imbalance between activating and inhibitory KIRs, the established by us protective effect of KIR genotype consisting of six activating KIRs may be considered a mediator of predominantly activating NK-receptor signals. The complex influence of KIRs for disease susceptibility is also supported by the observed protective effect of KIR genotype composed of 4 activating KIRs and 6 inhibitory KIRs, ratio 0.67 . Moreover, we found common protective KIR genotypes for HBV infection and leukemia suscepti- 
bility in the Bulgarian population, supporting the suggestion that identical genetic factors may contribute to both antiviral and antileukemic NK cell activity ${ }^{29}$.

The control of NK cell function mediated by expressed KIRs depends largely on the binding of KIRs to their appropriate ligands. There is a hierarchy in the strength of the inhibitory signal produced by KIRs binding to their respective HLA Bw4 ligands: HLA- $B w 4^{\text {Ile } 80}>\mathrm{HLA}-B w 4^{\text {Thr } 80}$ $\left(\right.$ ref. $\left.{ }^{10}\right)$. The lowest frequency of the stronger inhibitory receptor ligand group HLA-Bw4 ${ }^{\text {Ile80 }}$ in spontaneously recovered patients in the present study may indicate more effective NK antiviral defense contributing to the resolution of infection. Impact of HLA-Bw4 ${ }^{\text {lle } 80}$ ligands on the clinical course of HBV infection was reported by other authors as well. Shah-Hosseini et al. found activating KIR3DS1+HLA-Bw4 $4^{\text {Ile80 }}$ combination more frequently in $\mathrm{HBV}$ recovered individuals than in healthy controls ${ }^{17}$. Moreover, the more potent HLA-Bw4 $4^{\text {Ile } 80}$ ligands for inhibitory KIR3DL1 were associated with an increased incidence of hepatocellular carcinoma in HBV infected patients ${ }^{4}$.

Several research groups have reported correlations of certain KIR/HLA class I combinations with HBV infection evolution and outcome $\mathrm{e}^{4,6,13-17,20-22,25,27,30}$. In the present study no associations with chronicity or spontaneous recovery from HBV infection according to KIR HLA class I ligand combinations were found after correction of the $\mathrm{p}$ value. This lack of associations to some extent contradicts the hypothesis of genetically determined activity of the immune response mediated by inhered KIR/HLA class I combination. However, a limitation of the presented study must be noted related to the smaller number of patients enrolled, especially in the group of resolved HBV infection.

\section{CONCLUSION}

There is growing evidence for associations of KIRs and HLA ligand polymorphisms with the outcome of hepatitis viral infections and the present study provides additional data to these findings. However, the exact mechanism of action of the activating and inhibitory KIRs is still unknown. This study is the first comprehensive investigation in the Bulgarian population on genes related to NK cell function - KIRs and their HLA ligands in patients with hepatitis B infection. Our initial results suggest a possible role of the KIR/HLA ligand genetic profiles for viral persistence and chronification of $\mathrm{HBV}$ infection. The correlation between certain KIR/HLA genotypes and effectiveness of interferon- $\alpha$ therapy in patients with HBV infection should also be noted and should be considered as a proof for the role of KIR on NK mediated antiviral defense $\mathrm{e}^{27}$. In this sense the recognition of immunogenetic factors influencing innate $\mathrm{NK}$ responses, and associated with protection against or predisposition to chronic HBV infection may help to develop new treatment options in addition to specific antiviral therapy. The purpose of such combined strategy would be to personalize therapy, shorten the period of active infection, and reduce cases of chronicity and late complications associated with viral infections.

Author contributions: VV, GP, VG, DP, EN, AM: manuscript writing; VV, GP, VG, DP, EN, AM: manuscript revision.VV, AM: literature search, manuscript writing and final approval; VG: written English correction, VV, AM: critical reading, final approval.

Acknowledgement: This study was partly supported by a grant from the National Scientific Fund (DTK02/122009).

Conflict of interest statement: The authors state that there are no conflicts of interest regarding the publication of this article. None declared.

\section{REFERENCES}

1. Cristina S,Caterina S, Voller F. Emerging Trends in Epidemiology of Hepatitis B Virus Infection. J Clin TransI Hepatol 2017;5(3):272-76.

2. Global Hepatitis Report 2017. Geneva: World Health Organization; 2017. Licence: CC BY-NC-SA 3.0 IGO. Available from: https://apps. who.int/iris/bitstream/handle/10665/255016/9789241565455-eng. pdf;jsessionid=38B5E0E5E6300DAA1792A8B312F8224A?sequen $\mathrm{ce}=1$

3. Kevorkyan A, Teoharov P, Lernout T, Petrova N, Raycheva R, Ivanov I, van Damme P, Kojouharova M. Prevalence of HBV and HCV Among Outpatients in the Plovdiv Region of Bulgaria, 2010-2011. J Med Virol 2015;87(3):401-6.

4. Pan N, Jiang W, Sun H, Miao F, Qiu J, Jin H, Xu J, Shi Q, Xie W, Zhang J. KIR and HLA loci are associated with hepatocellular carcinoma development in patients with hepatitis $B$ virus infection: a case-control study. Plos One 2011;6(10):e25682.

5. Pan N, Qiu J, Sun H, Miao F, Shi Q, Xu J, Jiang W, Jin H, Xie W, He Y, Zhang J. Combination of human leukocyte antigen and killer cell immunoglobulin-like receptor genetic background influences the onset age of hepatocellular carcinoma in male patients with hepatitis B virus infection. Clin Dev Immunol 2013;2013:874514.

6. Auer ED, Tong TV, Amorim LM, Malheiros D, Hoan NX, Issler HC, Petzl-Erler ML, Beltrame MH, Beate A, Boldt W, Toan NL, Song LH, Velavan TP, Augusto DG. Natural killer cell receptor variants and chronic hepatitis B virus infection in the Vietnamese population. IJID 2020;96:541-47.

7. Martin AM, Freitas EM, Witt CS, Christiansen FT. The genomic organization and evolution of the natural killer immunoglobulin-like receptor (KIR) gene cluster. Immunogenetics 2000;51(4-5):268-80.

8. Collona M, Samaridis S. Cloning of immunoglobulin-superfamily members associated with HLA-C and HLA-B recognition by human natural killer cells. Science 1995;268:405-8.

9. D'Andrea A, Chang C, Franz-Bacon K, McClanahan T, Phillips JH, Lainner LL. Molecular cloning of NKB1. A natural killer cell receptor for HLA-B allotypes. J Immunol 1995;155(5):2306-10.

10. Cella M, Longo A, Ferrara GB, Strominger JL, Colonna M. NK3-specific natural killer cells are selectively inhibited by Bw4-positive HLA alleles with isoleucine 80. J Exp Med 1994;180(4):1235-42.

11. Thananchai H, Gillespie G, Martin MP, Bashirova A, Yawata N, Yawata M, Easterbrook P, McVicar DW, Maenaka K, Parham P, Carrington M, Dong T, Rowland-Jones S. Cutting edge: allele-specific and peptidedependent interactions between KIR3DL1 and HLA-A and HLA-B. J Immunol 2007;178(1):33-7.

12. Marsh SGE, Parham P, Dupont B, D.E. Geraghty DE, Trowsdale J, Middleton D, Vilches C, Carrington M, Witt C, Guethlein LA, Shilling H, Garcia CA, Hsu KC, Wain H. Killer-cell immunoglobulinlike receptor(KIR) nomenclature report, 2002. Tissue Antigens 2003;62:79-86.

13. Zhi-ming L, Yu-lian J, Zhao-lei F, Chun-xiao W, Zhen-fang D, Bingchang Z, Yue-ran Z. Polymorphisms of killer cell immunoglobulinlike receptor gene: possible association with susceptibility to or clearance of hepatitis B virus infection in Chinese Han population. Croat Med J 2007;48(6):800-6. 
14. Lu Z, Zhang B, Chen S, Gai Z, Feng Z, Liu X, Liu Y, Wen X, Li L, Jiao Y, Ma C, Shao S, Cui X, Chen G, Li J, Zhao Y.Association of KIR genotypes and haplotypes with susceptibility to chronic hepatitis B virus infection in Chinese Han population. Cell Mol Immunol 2008;5(6):457-63.

15. Kibar F, Oztuk OG, Ulu A, Erken E, Inal S, Dinkci S, Kurtaran B, Tasova Y,Aksu HSZ, Yaman A. Role of KIR genes and genotypes in susceptibility to or protection against hepatitis $B$ virus infection in a Turkish cohort. Med Sci Monit 2014;20:28-34.

16. Di Bona D, Aiello A, Colomba C, Bilancia M, Accardi G, Rubino R, Giannitrapani L, Tuttolomondo A, Cascio A, Caiaffa MF, Rizzo S, Di Lorenzo G, Candore G, Duro G, Macchia L, Montalto G, Caruso C; KIRIIND (KIR Infectious and Inflammatory Diseases) Collaborative Group. KIR2DL3 and the KIR ligand groups HLA-A-Bw4 and HLA-C2 predict the outcome of hepatitis B virus infection. J Viral Hepat 2017;24(9):768-75.

17. Shah-Hosseini A, Jafari M, Mohammadi A, Sanaei R, Alavian SM, Doosti-Irani A, Nooradeh Keykavousi M, Tajik N. The impact of KIRHLA genotype on hepatitis B virus clearance in Iranian infected individuals. Med Microbiol Immunol 2017;206(6):463-70.

18. Yindom LM, Mendy M, Bodimeade C, Chambion C, Aka P, Whittle HC, Rowland-Jones SL, Walton R. KIR content genotypes associate with carriage of hepatitis B surface antigen, e antigen and HBV viral load in Gambians. PLoS One 2017;12(11):e0188307.

19. Araujo $P$, Gonçalves $G$, Latini F, Ferreira O, Porto LC, Barreto JA, Girao MJ, Diaz RS. KIR and a specific HLA-C gene are associated with susceptibility and resistance to hepatitis B virus infection in a Brazilian population. Cell Mol Immunol 2014;11(6):609-12.

20. Kalyanaraman N, Thayumanavan L, Jayalakshmi M. KIR HLA association with clinical manifestations of HBV infection in Madurai, south India. J Genet 2016;95(1):13-9.

21. Sorgho PA, Martinson JJ, Djigma FW, Yonli AT, Nagalo BM, Compaore TR, Obiri-Yeboah D, Diarra B, Sombie HK, Zongo AW, Ouattara AK, Soubeiga STR, Traore L, Roberts LR, Simpore J. Insights into the Interplay between KIR Gene Frequencies and Chronic HBV Infection in Burkina Faso. Mediterr J Hematol Infect Dis 2018;10(1):e2018060.
22. Georgieva A. Research on immunogenetic markers related to the course of hepatitis B viral infection. Thesis, Sofia, 2016. https://www. ebi.ac.uk/ipd/kir

23. Varbanova V, A Mihaylova, E Naumova. Olerup SSP KIR HLA ligand typing Kit. A new opportunity for KIR ligand assignment in clinical settings. C R Acad Bulg Sci 2010;63(5):713-22.

24. Gonzalez-Galarza FF, McCabe A, Santos EJ, Jones J, Takeshita LY, Ortega-Rivera ND, Del Cid-Pavon GM, Ramsbottom K, Ghattaoraya GS, Alfirevic A, Middleton D and Jones AR. A llele frequency net database (AFND) 2020 update: gold-standard data classification, open access genotype data and new query tools. Nucleic Acid Research 2020;48:D783-8.

25. Karabon L, Jedynak A, Giebel S, Wołowiec D, Kielbinski M, Woszczyk D, Kapelko-Slowik K, Kuliczkowski K, Frydecka I. KIR/HLA gene combinations influence susceptibility to B-cell chronic lymphocytic leukemia and the clinical course of disease. Tissue Antigens 2011;78:129-38.

26. Stelma F, Jansen L, Sinnige MJ, van Dort KA, Takkenberg RB, Janssen HL, Reesink HW, Kootstra NA. HLA-C and KIR combined genotype as new response marker for $\mathrm{HBeAg}$-positive chronic hepatitis $\mathrm{B} \mathrm{pa-}$ tients treated with interferon-based combination therapy. J Viral Hepat 2016;23(8):652-9.

27. Pando M, Gardiner C, Gleimer M, McQueen K, Parham P. The protein made from a common allele of KIR3DL1 (3DL1*004) is poorly expressed at cell surfaces due to substitution at positions $86 \mathrm{in} \mathrm{lg}$ domain 0 and 182 in Ig domain 1. J Immunol 2003;171:6640-49.

28. Varbanova VP, Mihailova S, Naumova E, Mihaylova AP.Certain Killer immunoglobulin like receptor (KIR)/ KIR HLA class I ligand genotypes influence NK antitumor activity in acute myelogenous leukemia but not in acute lymphoblastic leukemia. A case control leukemia association study. Turk J Haematol 2019;36(4):238-46.

29. Gao S, Jiao B, Hong W, Cai C, Zhong Y, Quan Z, Chen H, Xu Y. Distribution of KIR/HLA alleles among ethnic Han Chinese patients with hepatocellular carcinoma from southern China. 2019:36(5):43942. doi: 10.3760/cma.j.issn.1003-9406.2019.05.006 (in Chinese) 